\title{
Dual Nature in the Creation of Disciplinary Identity: A Socio-historical Review of Palaeolithic Archaeology in Japan
}

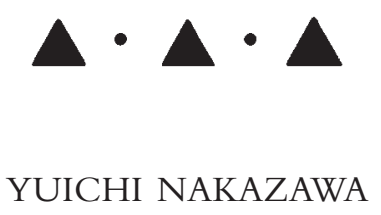

INTRODUCTION

IN CONTEMPORARY ARCHAEOLOGY, disciplinary identity is not only established by the scholarly activities within a particular scientific community, but also can be framed through transformations in relationships among various social organizations and individuals that are heavily influenced by the historical trajectory of social circumstances. The present article clarifies how this dual nature plays a role in creating disciplinary identity, by explicating how Palaeolithic archaeology in Japan has developed as a scientific discipline. Through a review of last 50 years of Palaeolithic research, changes in the roles of social organizations and individuals are evaluated in the peculiar context of modern Japanese archaeology.

\section{PALAEOLITHIC RESEARCH IN JAPAN}

\section{Research History}

Palaeolithic research in Japan has gone on for more than half a century, since the first recognition of a Pleistocene archaeological site — the Iwajuku site, about $90 \mathrm{~km}$ north of Tokyo - in 1949 by Tadahiro Aizawa, an amateur archaeologist who found lithic artifacts from Pleistocene sediments in a road profile, followed by an excavation conducted by academic archaeologists from Meiji University in Tokyo (Sugihara 1956; see also Aikens and Higuchi 1982; Imamura 1996). The history of research into human antiquity in the Pleistocene, however, is much shorter in Japan than in Europe. Indeed, European research on what was termed the "Old Stone Age" began in the early to mid-nineteenth century with the discovery of stone tools in association with extinct animals in the Somme Valley of northwestern France by Boucher de Perthes, followed by the recognition of human antiquity by Edouard Lartet and Gabriel de Mortillet among others (Sackett 1981; Trigger 1989:90-99). The first discoveries of Palaeolithic sites in Japan were different from those of Europe in several ways.

Yuichi Nakazawa, Ph.D., is an archaeologist with the Zao Board of Education, Miyagi, Japan, and Adjunct Assistant Professor with the Department of Anthropology, University of New Mexico. 
First of all, unlike the association of artifacts and extinct animals, the first Pleistocene sites in Japan lacked organic remains. The discoveries of human bones have been restricted to several sites, notably the Minatogawa 1 skeleton in Okinawa Island (Baba et al. 1998) and the Hamakita is in Honshu (Kondo and Matsu'ura 2005), although in both cases there is no evidence of associated artifacts. The lack of faunal remains in archaeological sites is also common. This is different from terminal Pleistocene sites recovered in North America, where the Folsom points were first discovered in association with bison bones (Meltzer 1983). In Japan, stone artifacts have largely been recovered without other human activity identifiers from Pleistocene sediments, sediments that are often visually distinct from the overlying dark Holocene humic soils (Watanabe and Sakagami 1999). The lack of faunal remains from Pleistocene sites is still common in more recent work on the Palaeolithic (Akazawa 1999; Nakazawa and Izuho 2006) and this "organically sterile" condition is also generally maintained in later prehistoric sites (i.e., from Jomon and Yayoi periods) except in special types of sites such as shell middens, karstic caves, water-logging, and bog sites (Habu 2004 : 214221). This preservation bias is caused by the humid environment and the high acidity of sediments in Japan (Barnes 2004). Besides the recognition of a stratigraphic position commensurate with a probable Pleistocene date and a lack of pottery, not enough evidence (e.g., radiometric dates, association of extinct animals) was present to securely establish the notion of the Palaeolithic in this early stage of Palaeolithic research.

This situation is clearly reflected in the culture-historical term of "Preceramic" that designates the Pleistocene Palaeolithic period in Japan (e.g., Ohyi 1968, 1978; Sugihara 1965; Tozawa 1990). Because of this preservation bias, research became heavily skewed toward lithics. Comparisons of lithic technology and diagnostic stone tool types (e.g., transverse burins, blade and microblade technologies) showed similarities with already known Palaeolithic cultural traits in Europe and North Asia (e.g., Serizawa 1959). Diagnostic tools such as large blades and bifaces were used as a fossil directeur (Rolland and Dibble 1990 : 481; Sackett 1981) to establish cultural chronologies within stratigraphic sequences (Sugihara 1965), and classification schemes developed in Europe were referred to in classifying the lithic artifacts from Japanese Pleistocene sites (Akazawa et al. 1980). However, systematic application of chronometric dating methods, especially ${ }^{14} \mathrm{C}$, to Palaeolithic sites was not common, a methodological deficiency that continued in attempts at cultural chronology in the Jomon period. At Jomon sites, ${ }^{14} \mathrm{C}$ dates were also rarely incorporated into the technical regimen associated with dating deposits, despite the fact that the emergence of early pottery was a significant milestone in Japanese prehistory (Habu 2004; Imamura 1996; Serizawa 1979). The reliance on non-radiometric dating is partially because of remarkable Pleistocene sediments that contain a variety of marker tephras that are present across regions (Machida and Arai 1992). The use of marker tephras, in collaboration with Quaternary geologists, allowed archaeologists to develop inter-site cross-dating comparisons to construct generalized regional Pleistocene cultural chronologies, especially in the southern Kanto Plain in and around Tokyo (e.g., Akazawa et al. 1980; Oda and Keally 1979; Yajima and Suzuki 1976), the southern skirt of Mt. Fuji (e.g., Takao 2006), southern Kyushu, southern Japan (Miyata 2006), and the central and southeastern plains in Hokkaido, northern Japan (Izuho and Akai 2005; Nakazawa et al. 2005; Terasaki and Yamahara 1999). On the other hand, Japanese archaeologists were not resistant to radiometric dating techniques per se in opposition to typeartifacts and stratigraphic contexts. Obsidian hydration as a dating method was applied 
to obsidian artifacts from several Palaeolithic sites in eastern Hokkaido (Katsui and Kondo 1965) where site stratigraphy and soil are poorly developed (Tsurumaru 2001).

Research on Palaeolithic sites has increased since the 1970s, which coincides with a time of economic growth in the Japanese nation (Sato 1992; Tsurumaru 2001). A cultural heritage law known as the "Protection of Cultural Properties" (Bunkazai Hogoho), enacted in 1950 and amended in 2006, regulates the designation and protection of cultural properties including historic towns, archaeological sites, art works, folklore, traditional music, dramas, festivals, and cultural landscapes (Agency of Cultural Affairs 2007). This law was commissioned by the Agency for Cultural Affairs, an administrative organization in the Ministry of Education, Culture, Sports, Science, and Technology in the national government. According to the Protection of Cultural Properties regulations, archaeological resources are categorized as "Burial Cultural Properties." Unlike arid and semi-arid regions, such as the U.S. Southwest, the probability of site identification in surface contexts is considerably less likely than that of sub-surface exposure through excavation, except in cultivated agricultural fields and in the case of existing large surface structures (e.g., burial mounds, historic shrines), because most of the sites are not visible from the surface due to the presence of dense vegetation and urbanization.

Government archaeologists, usually affiliated with the board of education of a local administrative office or affiliated with an "archaeological resource center" funded by a prefecture or municipal government (K. Okamura 2000:60), generally conduct excavations of the sites in association with plans for land modifications such as road and building constructions, under the principle of heritage protection (Agency of Cultural Affairs 2007; Barnes 1990; Habu 1989). In terms of the role of archaeologists, this is essentially identical to the Archaeological Resources Protection Act (ARPA) of the United States, enacted in 1979 (King 2004). However, differing from the United States' cultural heritage law, regardless of the categories of land ownership, salvage excavations are required in all kinds of lands, both public and private. Because some major burial mounds in the Iron Age (Kofun) Period are administratively registered as emperor's burials, they are given exceptional treatment as non-invasive cultural property and archaeologists are not usually allowed to excavate these sites (Tsude 1995). Salvage archaeological excavations are conducted by archaeologists affiliated with local governmental bodies, although they are centrally controlled by the national government. This administrative system that organizes cultural resources nationally and locally is symbolically labeled as "bureaucratic archaeology" (Barnes 1990). In this system, various offices or agencies carefully organize all archaeological research (mainly excavations, laboratory analyses, and publishing site monographs) in different government units (i.e., prefectures, cities, and towns). This system facilitates the central registration of sites by archaeologists and keeps track of basic information on the cultural remains found at various sites. By 2006, a total of 440,000 sites had been registered from all of the 47 prefectures (Agency of Cultural Affairs 2007). Materials recovered from the excavations, once reported in government publications, are curated in local historical museums or stored at the educational boards' administrative offices, where interested researchers (i.e., government and academic archaeologists, students) can access the materials and field notes for examination. In addition, as the number of excavations increased, the number of government archaeologists increased. According to statistics announced by the Agency of Cultural Affairs in 2003, a total of 7075 fulltime employees were engaged in excavations and laboratory work, and as many as 


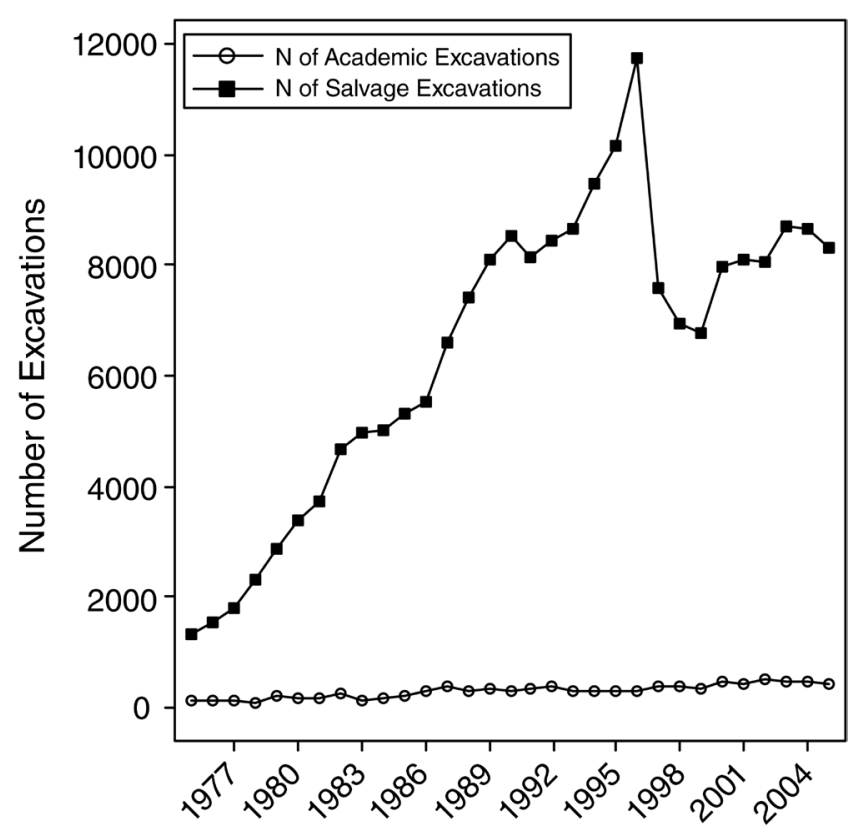

Fig. 1. The number of archaeological excavations in Japan, comparing academic and salvage projects between late $1970 \mathrm{~s}$ and the early 2000s.

8076 sites were excavated that year (Tamura 2006). Given the relatively small landmass of Japan $\left(377,838 \mathrm{~km}^{2}\right)$, this number is incredible. As shown in Figure 1, the number of salvage excavations dramatically increased from the 1970 s to the late 1990s. Although the rate of increase was not significant during the last ten years, the number of excavations currently reaches more than 7000 per year.

\section{Cultural and Temporal Framework of the Palaeolithic Record}

Because of this cultural regulation and an increase in land modification across the archipelago, the number of registered Palaeolithic sites has dramatically increased. In some urban areas with dense populations, especially Tokyo Metropolis in the southern Kanto Plain, deeply stratified open-air sites have been excavated and the everincreasing number of discovered sites has further accelerated the establishment of a regional cultural chronology for Honshu. Diachronic changes in the overall lithic technology and particularly the stone tool components of assemblages have been traced in detail using stratigraphic sequences (e.g., Akazawa et al. 1980; Oda and Keally 1979; Reynolds and Kaner 1990). At the same time, type lists of stone tools were developed by referring to classification systems used in the Western European Palaeolithic (Akazawa et al. 1980). Despite the accumulation of an extensive Palaeolithic record, which was primarily published by government offices in a comparable style to the cultural resource reports of the United States, the larger significance of the excavated sites has been of little concern (Tsutsumi 1996), and has been rarely synthesized within the larger geographical and cultural/temporal framework of the Japanese Islands (Sato 1992). Taking advantage of well-established culture-stratigraphic sequences that allowed archaeologists to perform inter-assemblage typological comparisons, efforts at synthesizing the Palaeolithic record in the archipelago (e.g., Ikawa-Smith 2004; 
M. Okamura 1990; Sato 1992; Tozawa 1990) have occasionally reached out to the larger national and international archaeological communities. Despite these efforts, the unfortunate tendency to circulate information only among handfuls of regional professionals still impedes the formulation of broad synthesis (Izuho 2007a).

This is essentially a "side effect" of the system of administrative archaeology in which archaeologists' research activities tend to be physically restricted to their local area (e.g., at most a few cities and towns within a prefecture). They do not have enough flexibility in their priorities to observe comparative materials and can spare little time to contemplate significant research issues beyond the mere establishment of local culture history (K. Okamura 2000; Tsude 1995). To figure out any nearby site's position in an existing regional cultural chronology, it is usually necessary to search for similar records in nearby governmental units (e.g., towns, cities) because a fundamental obligation for government archaeologists is to know the local and regional cultural history. In contrast, comparison across the borders of a larger administrative unit (i.e., prefectures) is less frequent, because the prefecture is treated as having maximum "political autonomy" within which results of annual salvage excavations are regularly circulated (K. Okamura 2000:61). Therefore, the degree of interest of an individual government archaeologist to extend the research area outside semi-autonomous political boundaries in an individual prefecture is determinative. Because Palaeolithic social networks (Wobst 1976) as suggested by the circulation of lithic raw materials, stylistic traits of stone tools, and variations in lithic technology often cross over modern political boundaries (Reynolds and Kaner 1990), most Palaeolithic archaeologists affiliated with government offices should go beyond the boundaries of modern political units to establish broader cultural chronologies.

In response to the dramatic increase in the number of Palaeolithic assemblages, researchers have continuously revised chronological frameworks of Palaeolithic industries. However, not all researchers share an identical chronological framework in which to place lithic assemblages into temporal sequences due to the following factors. First of all, most Palaeolithic archaeologists in Japan have formulated classification of stone tools based on differences in morphology (e.g., shape) and overall size (i.e., large vs. small), assuming that recognized differences are representative of regional makers and sensitive to time. The diversification of stone tool types is particularly pronounced among the knife-shaped tools (made on blades and flakes), which consistently occurred in the assemblages dated between c. 30,000 and 15,000 B.P. Unlike the popularity of stone tool typologies intended toward chronological reconstructions, functional differences among various types are rarely explored, and therefore the idea that some variation in stone tools may reflect differing economic strategies in prehistoric populations (Binford and Binford 1966) is not taken into account in building chronological frameworks. Secondly, densities of lithic material at sites vary among different regions due to modern factors of discovery. Because a number of Palaeolithic sites have been discovered in large contract projects under the Protection of Cultural Properties regulation, density distributions of Palaeolithic sites are largely influenced by the intensity of land modification and construction in particular locales. For example, 50 percent of size variation in the Upper Palaeolithic lithic assemblages in central Hokkaido is explained by trench size (Izuho and Nakazawa 2006).

Besides the problems of bias toward chronological explanations in stone tool typologies and uneven conditions for site discoveries, not many Palaeolithic sites can provide secure chrono-stratigraphies, characterized by undisturbed stratigraphic 
sequences that are tightly associated with reliable chronometic dates. In areas where chrono-stratigraphies are rarely given (e.g., southwestern and northeastern Honshu), researchers have been obliged to build chronologies by exclusively relying on selected attributes of lithic industries, including tool assemblage variability, morphological changes in formal stone tool classes, variation in raw materials, and variability in core reduction methods (e.g., Fujino 2006; Yanagida 2006). Because of these limitations, chronologies are still hypothetical because a very small fraction of the sites have yielded distinctive stratigraphic sequences that allow tracing changes in lithic assemblages (Fujino 2006:176). While debates on chronological frameworks will continue, given the prevalence in micro-regional diversity created by complex topographic conditions (e.g., lagged coastal lines, rivers, lacustrine environment, basins, low and high plains, hills, chains of mountains) in the Japanese Islands (Izuho 2007b), observed differences in lithic reduction technologies and tool morphologies at the regional scale are not necessarily regarded as the result of technological drift, but could have been explained by organizational solutions to the spectrum of biogeographic conditions in the Islands (e.g., variation in density and distribution of patches in a habitat, interregional variability in biomass).

Based on the recent efforts of cross-dating methods of the late Upper Pleistocene (e.g., Sato 2006; Ono et al. 2004; Sato 2006), three transitions are recognized in the early and late periods of the Upper Palaeolithic with: pre-Upper Palaeolithic/ Upper Palaeolithic, early Upper Palaeolithic (EUP)/late Upper Palaeolithic (LUP), and terminal Upper Palaeolithic/incipient Jomon. The division of early and late periods of the Upper Palaeolithic is based on changes in the frequencies of specific tool classes (disappearance of trapezoids and dominance of knife-shaped blades), roughly corresponding with the eruptive event of the marker tephra called AT (Aira-Tanzawa) that left a distinctive tephra layer in the Upper Pleistocene sediments at most localities in the archipelago, dated to c. 27,000 to 26,000 B.P. (Machida and Arai 2003). An attempt to synchronize the AT with marine sediments also shows that the EUP/LUP transition corresponded with the Oxygen Isotope Stages 3/2 boundary (Machida 2005). On the other hand, the transition from the LUP to the incipient Jomon is simply defined as the emergence of potteries, dated around 13,000 to 12,500 B.P. (Nakamura et al. 2001). Figure 2 displays the locations of regions where cultural chronologies were developed and Table 1 summarizes current chronologies compared across six regions for which regional chronologies have been proposed. The chronological frameworks are primarily built on the basis of normative methods in culture history: (1) similarities and differences in blank production technologies (e.g., blades, flakes, cobbles) and (2) presence and absence of major tool classes among the Japanese Palaeolithic records: trapezoids (trapezoidal flaked tools), knife-shaped blades, bifacial points, and microblades.

After the "Palaeolithic fake" scandal (see the discussion below), confirmative evidence of the earliest human occupations in the Japanese Islands was pushed forward in time to around 40,000 to 30,000 B.P. Secure stratigraphy for the earliest Upper Palaeolithic industries has been recorded from the deeply accumulated loam deposits in the Musashino and Sagamino Uplands on the southern Kanto Plain in western Tokyo. The topographic analysis of river terraces in the southern Kanto Plain shows that recurrent uplifts and erosions during the Upper Pleistocene created long sequences of terrace sediments, in which Upper Palaeolithic records were sealed (Kaizuka 1964). The cultural layer at the bottom of the Tachikawa Loam (Layer X) on the Musashino Upland started to accumulate around 40,000 B.P., while the charcoals securely ob- 


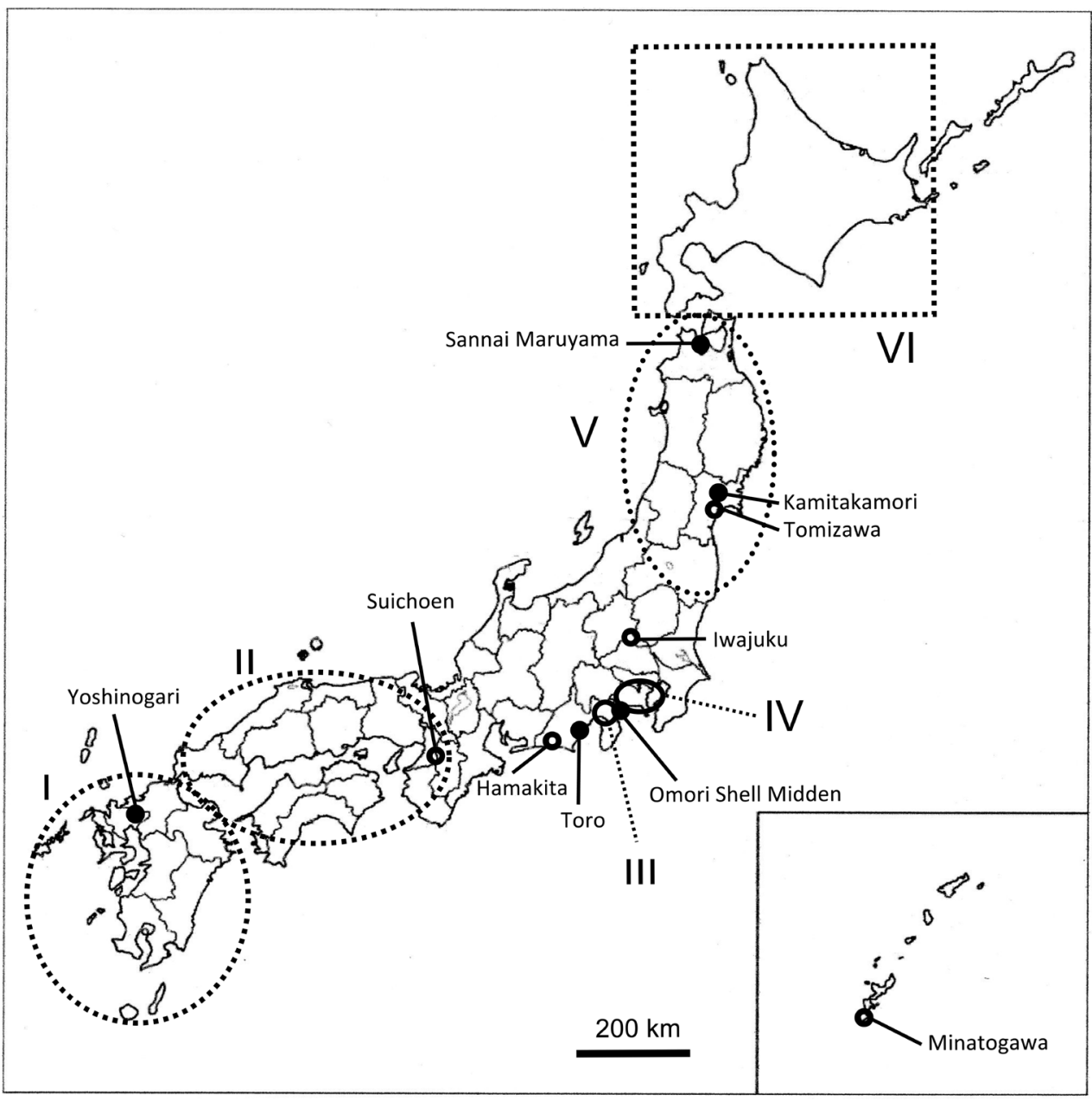

Fig. 2. The regions in Japan where Paaleolithic cultural chronologies have been constructed, as listed in Table 1. The site names as represented by circles are mentioned in the text. The open circles are the Palaeolithic sites, and the black filled circles are sites younger than Palaeolithic, except Kamitakamori in northern Japan, which has been eliminated from the list of registered archaeological sites.

tained from a hearth of the Palaeolithic occupation in Layer X at the Western District of the Musashidai site are dated to c. 30,000 B.P. (Yamaoka 2009:28). Outside the Kanto Plain, Hinatabayashi B site (Nagano, central Honshu) yielded the AMS radiocarbon dates of around 31,000 to 28,000 B.P., and the Ishinomoto site in northwestern Kyushu has AMS dates that fall between 34,000 and 31,000 B.P. (Ono et al. 2004: 480). Nevertheless, the number of lithic assemblages is still not large enough to assign a group of "pre-Upper Palaeolithic" or "middle Palaeolithic" industries. As more secure radiometric dates are obtained in future work at archaeological sites, the chances of obtaining older dates will increase, allowing the accurate definition of the beginning of the Upper Palaeolithic.

The beginning of the EUP is characterized by the appearance of trapezoids that are notably found among assemblages dated between 30,000 and 25,000 B.P. Trapezoids are the small flaked tools with retouched on natural or truncated edges of short and 


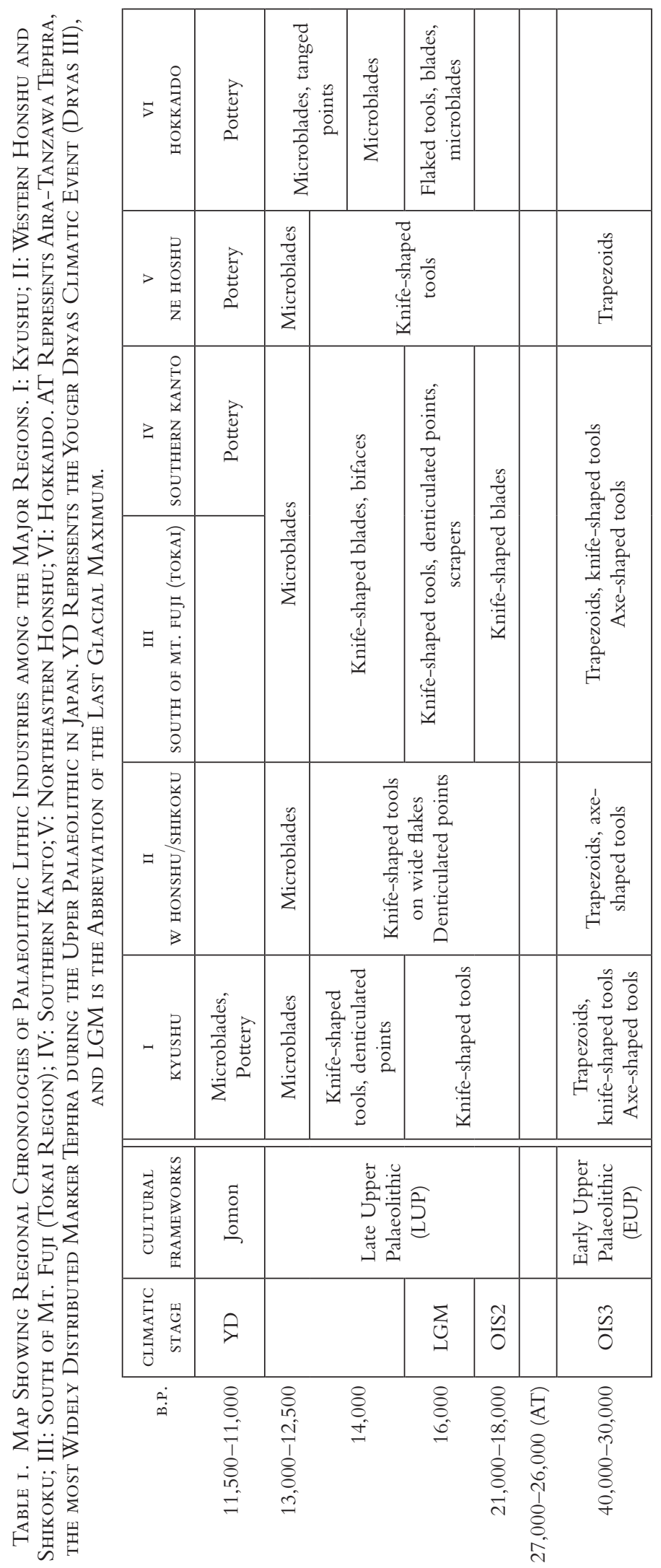


wide flake blanks made from flake cores. Since they are found among the EUP assemblages often associated with knife-shaped tools and axe-shaped tools made from cobbles, they are regarded as the representative tool class of the EUP. The edges of axe-shaped tools are often ground, suggesting that the earliest hunter-gatherers employed a stone-grinding technique by the time they started to settle the archipelago. During the EUP, flakes mostly served for making chipped stone tools, while blade technology was also employed in shaping knife-shaped tools in northeastern Honshu (Yanagida 2006).

Different from the EUP, the LUP lithic assemblages dated between 25,000 and 13,000 B.P. are characterized by increased variability in morphologies among chipped stone tools, from which researchers can define regionally bounded technocomplexes (e.g., Sugikubo, Higashiyama, Kou, Araya, Mikoshiba-Chojakubo). As the number of trapezoids decreased and axe-shaped tools disappeared, knife-shaped tools that are characterized by backed retouch often on truncated blades came to be the prevalent tool class in the assemblages at the onset of the LUP. Since Palaeolithic archaeologists have treated knife-shaped tools as a temporal type to construct cultural chronologies, numerous regional types of knife-shaped tools were identified. Among the variety of types, the "Kou Type" (Kamaki and Takahashi 1965) is one of the notable regional styles in knife-shaped tools during the LUP, because of its unique and systematic core reduction method that provided wide flakes for tool blanks, as well as its peculiar geographic distribution concentrated in southwestern Honshu. While knife-shaped blades are continually represented in the LUP assemblages, they are often associated with the denticulated points (probably functioning as projectile tips and/or scraping tools) that likely occurred during the Last Glacial Maximum (LGM) (c. 21,000-18,000 в.P.) and the bifacial points (presumably used for projectile tips) during the post-LGM period (c. 18,000-14,000 B.P.). By the onset of the terminal LUP period (c. 14,000-13,000 B.P.), microblade technology became the major tool blank production method, besides blade and flake production, except in Hokkaido where microblade production appeared during the LGM and was continually used until the onset of the incipient Jomon.

While the present view of cultural chronologies is a credible framework for understanding human occupational history in the Japanese Islands, it is still not certain how the earliest human occupation began and how far back in time the earliest evidence of human entry into this small but longitudinally elongated archipelago will ultimately be dated. Several lithic assemblages possibly older than the EUP have been recently reported from locations in Kyushu (e.g., Hagiwara 2006; Miyata 2006), although the pre-Upper Palaeolithic assemblages are still not only quantitatively insufficient, but also rarely studied compared to those of the EUP. Even a decade after the Palaeolithic scandal was exposed in 2000, continuing critiques from public and professional groups have influenced many Japanese Palaeolithic archaeologists to be wary of making committed claims of "digging-up" evidence of pre-Upper Palaeolithic occupation. However, it is still legitimate to investigate human occupation prior to 40,000 B.P. Unlike the LUP assemblages which can be grouped into some technocomplexes, the EUP assemblages are likely characterized by a low level of typological richness in tool assemblages (i.e., trapezoids, knife-shaped tools, and axe-shaped tools are often associated) and interregional variability in tool assemblages is low. Given these observations, the EUP technological characteristics represented by lithic industries may have been directly brought into the Islands with multiple waves of migrations or 
transmitted to Japan's indigenous populations from neighboring regions in southwestern or northeastern Asia. The validity of these ideas will be validly tested by systematic comparison of the Middle Palaeolithic/Upper Palaeolithic transitional industries in neighboring regions such as China, Korea, and the Russian Far East. Considering the geography of the Japanese Islands where modern humans should have arrived at the end of their long voyage from the mainland of Eurasia, it is doubtless that establishing the history of the earliest human occupation and exploring the evolutionary pathways that shaped the variability in Palaeolithic archaeological records will be a major undertaking in palaeoanthropology in East Asia. In this respect, a critical anthropological issue concerns what evolutionary factors influenced the emergence of variability in the Paleolithic technocomplexes in Japan's cul-de-sac geography during the Upper Pleistocene.

\section{THE PUBLIC AND ARCHAEOLOGISTS}

Given the recent decline in the number of salvage projects since the economic collapse in the early 1990s, the lack of synthesis and closed communication networks are not directly caused by a rapid pace of rescue excavations. In this article, I attempt to clarify that this is caused by peculiar relationships among academic archaeology, government archaeology, the public, and the media. The history of Palaeolithic discoveries in Japan tells us that Palaeolithic research in Japan was initiated through the collaboration of amateur and academic archaeologists, with contributions from Quaternary geologists who specialized in studying tephras. While salvage projects eventually took over this unique collaborative style of research, this tradition has been maintained at a small scale (e.g., Tsutsumi 1991, 1996). As the positive involvement of amateur archaeologists in the early stage of Japanese Palaeolithic research suggests, public interest in local and regional prehistory is widespread in Japanese society. Reacting against the emperor-centric perspective of history before and during World War II, which was intentionally constructed by political, military, and even academic authorities, archaeology as a discipline had a role of revealing hidden history by means of its own methods after World War II (Habu 1989; K. Okamura 2000; cf. Oguma 1995). The disciplinary method of archaeology was first introduced by the American biologist Edward S. Morse, who organized the excavation of the Jomon shell midden site of Omori (Tokyo) in 1877 (Bleed 1986; Morse 1879). As a trained biologist, he conducted high-quality research, using then-modern excavation techniques, with descriptions and illustrations of artifacts that influenced young Japanese archaeologists, and promoted subsequent archaeological research in Japan (Tozawa 1984). Current standards of excavation techniques and emphasis on detailed descriptions of archaeological materials maintained in archaeological reports to this day in Japan may have originated in this early stage of American influence, despite the fact that these habitats are currently regarded as peculiar characteristics of Japanese archaeology (Imamura 1996). As the Japanese government attempted to introduce new social and political systems and technologies from the western world (i.e., Europe and the United States) to aid in national economic development in the late nineteenth century after the Meiji Restoration in 1867, science was one of the fields to be reinforced under national policy. The archaeology brought by Morse was definitely accepted as new and innovative. "Scientific knowledge" was a foreign notion for the late nineteenthcentury Japanese, among other newly introduced socioeconomical and political sys- 
tems, such as banking systems and military organizations (Pyle 2007:30). While Morse's work influenced the debate on the ethnic origin of ancient Japanese (Oguma 1995 :20), an aspect of natural science in archaeological methods has not been fairly recognized in modern Japanese archaeology after WWII (Tozawa 1984). Post-World War II Japanese archaeology is a sub-discipline of national history that was expected to contribute to an establishment of real history (Fawcett 1995).

\section{THE PALAEOLITHIC HOAX SCANDAL}

This perception has been maintained until recently, when the Palaeolithic Hoax scandal was exposed and sensationally reported by one of the major national dailies (Mainichi Shinbun) in November 2000, as was recognized nationally and internationally (Normile 2001a, 2001c). The amateur archaeologist, Shin'ichi Fujimura, a leading member of the nonprofit organization of the Tohoku Paleolithic Cultural Research Institute that conducted excavations at a number of what are now known to be counterfeit early Palaeolithic sites across the Japanese Islands, brought the hoax to the attention of Japanese scholars and the public when he placed inauthentic stone implements into the Middle Pleistocene deposits at the Kamitakamori site in northern Japan.

When this hoax was exposed, a variety of criticisms were leveled against archaeologists working on Palaeolithic sites, from both scholars in archaeology and other disciplines. Among the major criticisms were both reasonable methodological questions, including the lack of systematic observation and valid techno-typological analysis of lithic artifacts from early Palaeolithic sites, and more sweeping claims that Palaeolithic archaeology or even Japanese archaeology in general was not grounded in science (Normile 2001a). The background of the hoax and its effect on archaeologists and on Japanese prehistory, as well as the results of reinvestigations into the registered early Palaeolithic sites (Ikawa-Smith 1982; Imamura 1996; Reynolds 1986) dating to older than 35,000-30,000 B.P. have been discussed and disseminated by professional archaeologists (e.g., Bleed 2000; Hudson 2005; Kaner 2002; Keally 2002; Matsumoto 2002; Tsurumaru 2001; Yajima 2004; Yamada 2002) and have been recognized to some extent by an international professional audience (Jaubert 2006). However, issues regarding the effects of the faked artifacts scandal on public perceptions of Japanese archaeology have been thus far of little concern.

Mass media has played a role in archaeology in Japan since after World War II (Fawcett 1995; Hudson 2005; Tsude 1995). Indeed, it was not unusual that newly discovered archaeological evidence would be published in the social affairs sections of newspapers on a daily basis prior to the Palaeolithic Hoax scandal. While this heavy commitment of mass media to archaeology enhanced the popularity of archaeology among the public (i.e., "affected groups" [Watkins et al. 2000:41]), as seen in the example of excavations at the Toro site that involved both archaeologists, amateurs, and local volunteers in two years after the end of World War II (Fawcett 1995), the current relationships among the media, the public, and archaeologists are different from the initial stage of modern Japanese archaeology. Apart from the Palaeolithic artifact scandal, the discussion below is focused on an analysis of the social structure (particularly the status structure) of Japanese archaeology in order to elucidate the specific organizational features and mechanisms that allowed for the creation and acceptance of a fake prehistory. 


\section{Academic Archaeology Versus Government Archaeology}

The Japanese academic system, originally introduced from Germany in the late nineteenth century, has maintained laboratory-based research sections, overwhelmingly controlled by senior professors. Within this closed system, described as being "patriarchal [and], top-down" (Normile 2001b:818), it has been rare for academic scholars to make contact with the public. However, as already mentioned, the involvement of amateur archaeologists in the early stage of Palaeolithic research (1940s-1950s) was an exception. Because academic archaeologists could not easily gain access to the sources of potential archaeological sites because they resided in urban areas, local amateurs often had better empirical knowledge than academic archaeologists and provided significant sources of information. In other words, amateur archaeologists were informants, and thus collaboration between amateur and academic archaeologists was inevitable in the initial stage of Japanese Palaeolithic research (Fig. 3). As government archaeology has dominated research since the 1970s, amateur archaeologists as informants were increasingly sidelined and isolated from academic archaeology (Fawcett 1995; Magara and Tsutsumi 1999:27), with the notable exception of the individual Shin'ichi Fujimura who conducted the search for "early Palaeolithic sites."

Because universities (particularly national and public ones) are part of an administrative system, there is an affinity between archaeologies in the academic and government settings in terms of their major source of funding. However, a fundamental difference in the goals and activities of academic and government archaeology should be emphasized. University professors are required to carry out original research, which in turn leads to more theoretical and methodological sophistication in the discipline and in science in general, while the primary goal of government archaeology is to protect cultural resources. Nevertheless, the amount of information gained from salvage projects became quantitatively much larger than that of academic research, as the number of excavations have grown significantly since the 1970s (Tamura 2006; see also Figure 1). Under these circumstances, if the research goal of an academic archaeologist was in the domain of local culture history, such as building cultural chronolo-

\section{$\underline{1950-60 ' s}$}

Scientific community

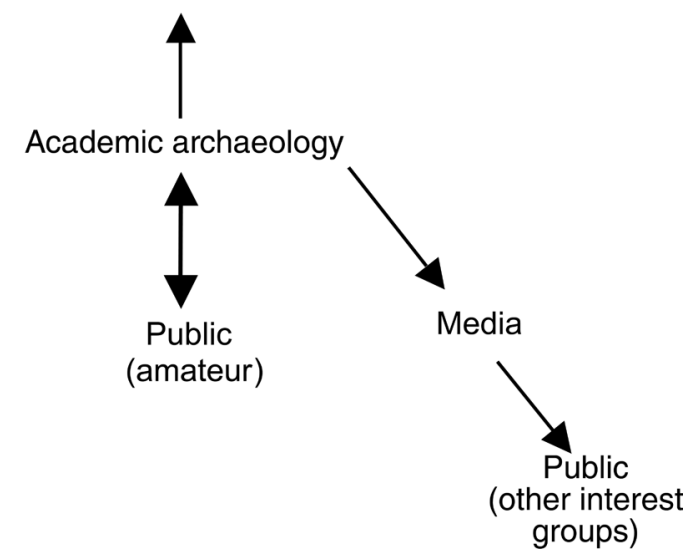

Fig. 3. A schematic illustration showing the relationships among the scientific community, academia, the public, and the media in Japan from the 1950s to the 1960s. 
gies, information flow from government archaeology was even more critical for academic archaeologists. However, a one-way flow of information from the government organizations concerned with archaeology to the academic realm does not benefit the government field archaeologists who are also interested in building local culture history. This unequal relationship between the two parties has recently become more balanced, as the universities started to train students to be applied archaeologists, who were later hired by local administrative offices as professionals (Barnes 1990 : 191). This "reciprocal" relationship between academic and government archaeology led to the modification of university course curriculum to be more oriented toward applied skills in salvage work (e.g., excavation technique, classification of materials, artifact illustrations) in place of individual problem-oriented research abilities. This trend is notably different from the academic programs in most U.S. universities, in which research issues are often not relevant to those in contract archaeology (Roberts et al. 2004:70). As salvage excavations increased, the boundary between academic and government archaeologies became more blurred. Although the relationship between academic and government domains is regarded as a "healthy interchange" (Barnes 1990:193), it represents a significant transformation of the nature of archaeology with respect to its goals and interests.

Ironically, in contrast to this transformation in the relationship between academic and government archaeologies, a nonprofit organization (Tohoku Paleolithic Cultural Research Institute) conducting research into the early Palaeolithic, mainly of northern Japan, was a group organized by non-government archaeologists (amateur and academic archaeologists) that had maintained an active commitment to collaboration with amateur archaeologists and public groups (e.g., local schoolteachers, students) in survey and excavations. The research was obviously goal-oriented, namely to search for evidence of early human occupation in the Japanese Islands that could contribute to building wider anthropological knowledge.

\section{GOVERNMENT ARCHAEOLOGY VERSUS THE PUBLIC}

Under the principle of the protection of cultural properties, the primary role of government archaeology is to designate the importance of a variety of cultural properties, including archaeological sites. Unlike for other cultural properties, the government regulation (Agency of Cultural Affairs 2007) states that excavations of archaeological sites discovered by construction projects are paid for by the projects (e.g., construction companies). Given that this financial responsibility is placed on the management of public companies, the government should have an ethical responsibility to the public to account for the work done in salvaging archaeological sites. This is partially achieved by exhibitions in museums at the prefectural and national levels. For example, the Agency of Cultural Affairs began to organize a special nationwide archaeological exhibition tour to publicly display in various municipal, prefecture, and national museums across Japan, remarkable collections of archaeological materials recovered by annual salvage excavations (Agency of Cultural Affairs 2007). This will further increase the amount of public interest in national history.

Under the principle of archaeological heritage management, sites are expected to be preserved in situ, protected from any destruction including excavation, although maintenance of this principle is difficult in densely populated areas (K. Okamura 2000). As a compromise, remarkable archaeological sites sometimes discovered by 
salvage projects are recognized as part of the regional heritage, which is later used to attract tourists. The role of cultural heritage in local tourism is particularly emphasized in rural prefectures where tourism has become a major source of income. The public display of archaeological sites often has positive effects on local economies, as shown by the protected sites of the Sannai Maruyama (Jomon) site in Aomori Prefecture, northern Japan (Habu 2004), and the Yoshinogari (Yoyoi) site in Saga Prefecture, southern Japan (Mizoguchi 2002), which have attracted large numbers of tourists. In contrast to these sites, Palaeolithic sites are often not preserved except in some cases such as the Suichoen site preserved as a city park of Osaka Prefecture, southwestern Japan, and the Tomizawa site as a city museum exhibition in Miyagi Prefecture, northern Japan. This public attention is greatly increased by rapid information transmission through the mass media.

\section{THE MASS MEDIA IN ARCHAEOLOGY}

When salvage excavations result in a significant discovery, the media tends to broadcast it to the public using information obtained from archaeologists in administrative offices. It is not unusual for the media to request comments on the newly discovered archaeological evidence from academic archaeologists, who are treated as authorities on local and national history. Before the Palaeolithic Hoax scandal was revealed, discoveries of new findings from prehistoric and historic archaeological sites, including the early Palaeolithic sites, were immediately disseminated to the public through the mass media (Fig. 4). This created much public attention and interest. It is doubtless the case that students interested in history, who can be categorized as an affected group, were led to specialize in archaeology and went into university programs as a response to the flood of cultural resource news from the mass media. Unfortunately, academic archaeologists did not live up to their responsibility to connect with government and amateur archaeologists to verify and incorporate this research through a process of systematic observations and data analyses that should have resulted in monographs and professional journal articles to be shared within the scientific community. The extent of public attention can also influence the acquisition of funding by government archaeologists from the governments where investigated sites are located, as local prefectures expected to get attention through potential new archaeological discoveries.

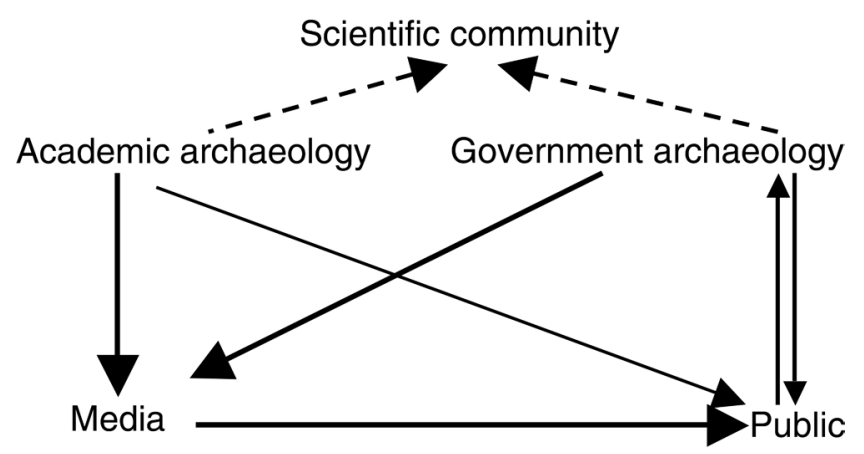

Fig. 4. A schematic illustration showing the relationships among the scientific community, academia, the public, and the media in Japan from the 1970 s to 2000 . 
As long as research was funded through the government and universities and each type of institution continued to interact as a relatively closed network of professionals, excavations continued and only superficial results were briefly disseminated to wider professional and public audiences. The oddly closed circulation of scientific results is not only seen in the groups involved in the Palaeolithic Hoax scandal, but also can be more generally recognized within Japanese archaeology.

To end this violation of normal scientific procedure, each professional archaeologist, regardless of his/her position-academic or government-based-should present the significant results of his/her research to both professional and public audiences. Having recognized that the excavated and analyzed Palaeolithic record is intellectual property (Chippindale and Pendergast 2000:52-56), breaking through the language barrier, disseminating the efforts of publication to peers, and organizing symposia in international meetings will be one of the legitimate ways in which to achieve this goal.

\section{CONCLUSIONS}

The growth of government archaeology was contingent on Japanese economic growth in the 50 years after the end of World War II. However, the Palaeolithic Hoax scandal should not be treated as an isolated phenomenon. It should be recognized as a predictable outcome of the history and structure of archaeology in Japan. Rather than seeing the scandal as the reflection of immaturity in the science of Palaeolithic archaeology, the status of transformed relationships among different organizations (i.e., academic archaeology, government archaeology, the public, and media) provides a better explanation as to why the hoax became a part of Palaeolithic research. As salvage work came to dominate current archaeology in conjunction with a deep commitment of the mass media to historical and archaeological issues, the basic structure of Japanese archaeology was created, consisting of three constituents-academia, government, and mass media. Meanwhile, responding to rapid increases in the number of site excavations, the feedback relationships among these constituents changed, with an internal reorganization oriented more toward minimizing the conflict of interest between academic archaeology and government archaeology. Consequently, these reorganized relationships hinged on the professionalism and accountability of Japanese archaeology, which instead broke down and allowed for continued construction of a fake prehistory over the last two decades.

As Woody (2003:25) has pointed out the coherent actions and thoughts of individuals, driven by the aims and values of the scientific community, provide a basis for the functioning of a scientific discipline. Given this statement about the nature of scientific disciplines, an appreciation of the aims and values of the particular scientific community is essential in evaluating the current status of disciplinary identity. I hope this pragmatic examination of the current status of Palaeolithic research in Japan will open up discussion about the development of disciplinary identity in archaeological research under given national and historical circumstances in various regions of the world.

\section{ACKNOWLEDGMENTS}

This article is based on the draft presented in the symposium Palaeolithic in Japan, at the SAA annual meeting in 2007. I thank all participants with whom I exchanged opinions 
about the issues of this paper, as well as the symposium discussants Profs. Peter Bleed and Robert Elston. I am also grateful to Profs. Peter Bleed, Lawrence Straus, and Elizabeth Stewart for reading various manuscripts and giving helpful comments. My special thanks go to Prof. Hisao Baba, Dr. Takashi Tsutsumi, Masami Izuho, Kohtaro Yoshikawa, Takuya Yamaoka, and Kosuke Matsuda for sharing valuable information. I am grateful to Dr. Laura Junker for her thorough editorial help and anonymous reviewers for their helpful comments.

\section{REFERENCES CITED}

Agency of Cultural Affairs

2007 Preserving and Utilizing Cultural Properties. Tokyo: Agency of Cultural Affairs.

Aikens, C. Melvin, and Takayasu Higuchi

1982 Prehistory of Japan. New York: Academic Press.

AKazawa, TAKeru

1999 Pleistocene peoples of Japan and the peopling of the Americas, in Ice Age Peoples of North America: Environments, Origins, and Adaptations: 95-103, ed. Robson Bonnichsen and Karen L. Turnmire. Corvallis: Oregon State University Press.

Akazawa, Takeru, Shizuo Oda, and Ichiro Yamanaka

1980 The Japanese Palaeolithic: A Techno-typological Study. Tokyo: Rippu Shobo (in English and Japanese).

Baba, Hisao, Shuichiro Narasaki, and Ohyama Seiho

1998 Minatogawa hominid fossils and the evolution of Late Pleistocene Humans in East Asia. Anthropological Science 106 (Supplement): 27-45.

BARnes, Gina L.

1990 The origin of bureaucratic archaeology in Japan. Journal of the Hong Kong Archaeological Society 12:183-196.

2004 Acid soils and acid rocks in Japan: Implications for bone preservation, in Recent Paleolithic Studies in Japan: Proceedings for Tainted Evidence and Restoration of Confidence in the Pleistocene Archaeology of the Japanese Archipelago: 68-88, ed. K. Yajima. Tokyo: The Japanese Archaeological Association.

Binford, Lewis R., and Sally R. Binford

1966 A preliminary analysis of functional variability in the Mousterian of Levallois facies. American Anthropologist 68:238-295.

BleEd, Peter

1986 Almost archaeology: Early archaeological interest in Japan, in Windows on the Japanese Past: Studies in Archaeology and Prehistory: 57-67, ed. R. J. Pearson, G. L. Barnes, and K. L. Hutterer. Ann Arbor: Center for Japanese Studies, University of Michigan.

2000 Digging out of the scandal. http://www.t-net.ne.jp/ keally/Hoax/keally-bleed2.html, accessed December 15, 2008. File possessed by the author.

Chippindale, Christopher, and David M. Pendergast

2000 Intellectual property: Ethics, knowledge, and publication, in Ethics in American Archaeology, 2nd rev. ed.: 52-56, ed. M. J. Lynott and A. Wylie. Washington, D.C.: Society for American Archaeology.

Faw CEtT, Clare

1995 Nationalism and postwar Japanese archaeology. in Nationalism, Politics, and the Practice of Archaeology: 232-246, ed. P. L. Kohl and C. Fawcett. Cambridge: Cambridge University Press.

Fujino, Tsugifumi

2006 The regional chronology of Chugoku, Shikoku, and southwestern Honshu, in A Study of Regional Chronologies of Paleolithic: 173-206, ed. Anzai Masahito and Sato Hiroyuki. Tokyo: Doseisha (in Japanese).

Habu, JunKo

1989 Contemporary Japanese archaeology and society. Archaeological Review from Cambridge 8:3645 .

2004 Ancient Jomon of Japan. Cambridge: Cambridge University Press. 
Hagiwara, Hirofumi

2006 The regional chronology of northwestern Kyushu, in A Study of Regional Chronologies of Paleolithic: 207-240, ed. Anzai Masahito and Sato Hiroyuki. Tokyo: Doseisha (in Japanese).

Hudson, Mark J.

2005 For the people, by the people: Postwar Japanese and the Early Paleolithic hoax. Anthropological Science 113:131-139.

IкAWA-Sмiтн, Fumiko

1982 The history of Early Paleolithic Research in Japan, in Early Paleolithic in South and East Asia: 247-286, ed. F. Ikawa-Smith. The Hague: Mouton.

2004 Humans along the Pacific margin of Northeast Asia before the Last Glacial Maximum: Evidence for their presence and adaptations, in Entering America: Northeast Asia and Beringia Before the Last Glacial Maximum: 285-309, ed. D. B. Madsen. Salt Lake City: University of Utah Press.

IMAMURA, KeIJI

1996 Prehistoric Japan: New Perspectives on Insular East Asia. London: UCL Press.

IzUHO, MASAMI

2007a Review and prospect, 2006, Archaeology, Paleolithic period. Historical Studies in Japan 116:619-624 (in Japanese).

$2007 b$ Pleistocene environment in Japan. Paper Presented at the 72nd Annual Meeting of the Society of American Archaeology, Austin, Texas.

Izuho, Masami, and Fumito Akai

2005 Geochronology of Palaeolithic sites in Hokkaido, Japan. Paleolithic Research 1:39-55 (in Japanese).

IzUHO, Masami and Yuichi NaKazawa

2006 On the variation of assemblage size in Late Pleniglacial Hokkaido: Sampling error or behavioral signature? Current Research in the Pleistocene 23:4-6.

JAUBERT, JACQUES

2006 Comptes rendus:Yajima K. dir. (2004). Bulletin de la Société Prehistorique Française 103(2) : 404406.

Kaizuka, SHohei

1964 The Natural History of Tokyo. Tokyo: Kinokuniya Shoten (in Japanese).

Kamaki, Yoshimasa, and Mamoru TaKahashi

1965 Preceramic Age in the Setouchi Region, in Japanese Archaeology I: Preceramic Age: 280-302, ed. Sugihara Sosuke. Tokyo: Kawade Shobo (in Japanese).

KANER, SIMON

2002 Trouble in the Japanese Lower and Middle Palaeolithic. Before Farming 2:1-23.

Katsui, Yoshio, and Yuko Kondo

1965 The age determination of lithic assemblages by means of measurements of obsidian hydration rims. Journal of Hokkaido Archaeological Association 1:1-18 (in Japanese).

Keally, Charles T.

2002 Dirt and Japan's Early Palaeolithic hoax. Sophia International Review 24:33-41.

King, Thomas F.

2004 Cultural Resource Laws and Practice: An Introductory Guide, 2nd ed. Walnut Creek: AltaMira Press.

Kondo, Megumi, and Shuji Matsu'ura

2005 Dating of the Hamakita remains from Japan. Anthropological Science 113:155-161.

Machida, Hiroshi

2005 A tephrochronological review on the earlier Paleolithic archaeological remains in south Kanto. Paleolithic Research 1:7-16 (in Japanese).

Machida, Hiroshi and Fusao Arai

1992 The Atlas of Volcanic Ash. Tokyo: University of Tokyo Press (in Japanese).

2003 The Atlas of Volcanic Ash, rev. ed. Tokyo: University of Tokyo Press (in Japanese).

Magara, Hiroshi, and Takashi Tsutsumi

1999 The Chubu region. Palaeolithic Archaeology 58:27-35 (in Japanese).

Matsumoto, NaOKo

2002 Update on the Japanese Early and Middle Palaeolithic problem. Before Farming 2:24-25. 
MeLtzer, David J.

1983 The antiquity of man and the development of American Archaeology. Advances in Archaeological Method and Theory 6:1-51.

Miyata, Eiji

2006 The regional chronology of southwestern Kyushu, in A Study of Regional Chronologies of Paleolithic: 241-273, ed. Anzai Masahito and Sato Hiroyuki. Tokyo: Doseisha (in Japanese).

Mizoguchi, KojI

2002 An Archaeological History of Japan: 30,000 B.C. to A.D. 700. Philadelphia: University of Pennsylvania Press.

Morse, Edward S.

1879 Shell Mounds of Omori, Memoirs Science Department. Tokyo: University of Tokyo.

Nakamura, Toshio, Yasuhiro Taniguchi, Seilchiro Tsuji, and Hirotaka Oda

2001 Radiocarbon dating of charred residues on the earliest pottery in Japan. Radiocarbon 43:11291138.

Nakazawa, Yuichi, and Masami Izuho

2006 Stone tool assemblage variability during the Last Glacial Maximum in Hokkaido. Current Research in the Pleistocene 23:26-28.

Nakazawa, Yuichi, Masami Izuho, Jun Takakura, and Satoru Yamada

2005 Toward an understanding of technological variability in microblade assemblages in Hokkaido, Japan. Asian Perspectives $44: 276-292$.

Normale, Dennis

2001a Japanese fraud highlights media-driven research ethic. Science 291:34-35.

$2001 b$ Women faculty battle Japan's Koza system. Science $291: 817-818$.

2001c Science scope. Science 294:31.

Oda, Shizuo, and Charles T. Keally

1979 Japanese Paleolithic cultural chronology. Paper presented at the XIVth Pacific Science Congress at Khabarovsk. File possessed by author.

Oguma, Eiji

1995 The Myth of the Homogeneous Nation. Tokyo: Shinyosha (in Japanese).

Ohyi, Haruo

1968 On the traditions of the preceramic industries in Japan. Bulletin of the Institute for the Study of North Eurasian Cultures, Hokkaido University 3:45-93.

1978 Some comments on the Early Paleolithic of Japan, in Early Paleolithic in South and East Asia: 299-301, ed. F. Ikawa-Smith. The Hague: Mouton.

OKamura, Katsuyuki

2000 Conflict between preservation and development in Japan: The challenges for rescue archaeologists, in Cultural Resource Management in Contemporary Society: 55-65, ed. Francis P. McManamon and Alf Hatton, London: Routledge.

OKAMURA, Michio

1990 History of Japanese Paleolithic. Yuzankaku, Japan (in Japanese).

Ono, Akira, Hiroyuki Sato, Takashi Tsutsumi, and Yuichiro Kudo

2004 Radiocarbon dates and archaeology of the Late Pleistocene in the Japanese Islands. Radiocarbon 44 : 477-494.

Pyle, Kenneth B.

2007 Japan Rising: The Resurgence of Japanese Power and Purpose. New York: Public Affairs.

REYNOLDS, T.E.G.

1986 Toward peopling the New World: A possible Early Palaeolithic in Tohoku District, Japan. American Antiquity 51:330-332.

Reynolds, T.E.G., And Simon C. Kaner

1990 Japan and Korea at 18000 B.P., in The World at 18000 BP, Vol. 1, High Latitudes: 296-311, ed. O. Soffer and C. Gamble. London: Unwin Hyman.

Rolland, Nicolas, and Harold L. Dibble

1990 A new synthesis of Middle Paleolithic variability. American Antiquity 55:480-490. 
Roberts, Heidi, Richard V. N. Ahlstrom, and Barbara Roth

2004 From Campus to Corporation: The Emergence of Contract Archaeology in the Southwestern United States. Washington, D.C: Society for American Archaeology.

SACKeTt, JAMES R.

1981 From de Mortillet to Bordes: A century of French Palaeolithic research, in Towards a History of Archaeology: 85-99, ed. G. Daniel. London: Thames and Hudson.

SATO, Hiroyuki

1992 The Structure and Evolution of the Japanese Paleolithic Culture. Tokyo: Kashiwa Shobo (in Japanese).

2006 The progress of chronological study in the Japanese Paleolithic, in A Study of Regional Chronologies of Paleolithic: 363-370, ed. Anzai Masahito and Sato Hiroyuki. Tokyo: Doseisha (in Japanese).

Serizawa, ChOSUKe

1959 On the microblade culture and Araya-type burins in the Araya site, Niigata Prefecture. The Quaternary Research 1(5):174-181.

1979 Cave sites in Japan. World Archaeology $10: 340-349$.

Sugihara, Sosuke

1956 A Lithic Culture Discovered at Iwajuku, Gunma Prefecture. Tokyo: Meiji University (in Japanese).

1965 Archaeology in Japan I. Tokyo: Kawadeshobo.

TAKAO, YOSHIYUKI

2006 The regional chronology of Tokai region, in Study of Regional Chronologies of the Paleolithic: 61-102, ed. Anzai Masahito and Sato Hiroyuki. Tokyo: Doseisha (in Japanese).

TAMURA, KOICHI

2006 The activities for preserving archaeological heritages by the Japanese Archaeological Association. Poster presented at the WAC Intercongress OSAKA, Osaka. File possessed by the author.

Terasaki, Yasufumi, AND Toshiro Yamahara

1999 Hokkaido region. Paleolithic Archaeology 58:3-10 (in Japanese).

Tozawa, Mitsunori

1984 The Jomon People and Shell Middens. Tokyo: Rokkou Shuppan (in Japanese).

1990 The Structure of the Japanese Preceramic Culture. Tokyo: Dohosha Shuppan (in Japanese).

Trigger, Bruce G.

1989 A History of Archaeological Thought. Cambridge: Cambridge University Press.

Tsude, Hiroshi

1995 Archaeological theory in Japan, in Theory in Archaeology: A World Perspective: 298-311, ed. Peter J. Ucko. London: Routledge.

TSurumaru, Toshiaki

2001 Contemporary issues and perspectives of Paleolithic archaeology. Journal of Hokkaido Archaeological Association 37:3-22 (in Japanese).

Tsutsumi, TAKASHi

1991 Archaeological Investigations at Nakappara 5, Loc. B. Hoozuki Shoseki, Nagano (in Japanese).

1996 Archaeological Investigations at Nakappara 1, Loc. G, Vol. II. Hoozuki Shoseki, Nagano (in Japanese).

Watanabe, Makiko, and Kan'ichi Sakagami

1999 Recent pedological approach to reconstruction of the Quaternary environment in Japan and East Asia. The Quaternary Research 38:244-252.

Watkins, Joe, Lynne Goldstein, Karen Vitelli, and Leigh Jenkins

2000 Accountability: Responsibilities of archaeologists to other interest groups, in Ethics in American Archaeology, 2nd rev. ed.: 40-44, ed. M. J. Lynott and A. Wylie. Washington, D.C.: Society for American Archaeology.

WOBST, H. MARTIN

1976 Locational relationships in Paleolithic society. Journal of Human Evolution 5 : 49-58.

WOODY, ANDREA I.

2003 On explanatory practice and disciplinary identity. Annals of New York Academy of Science 988:22-29. 
Yajima, Kunio

2004 Recent Paleolithic Studies in Japan: Proceedings for Tainted Evidence and Restoration of Confidence in the Pleistocene Archaeology of the Japanese Archipelago. Tokyo: The Japanese Archaeological Association.

Yajima, Kunio, and Jiro Suzuki

1976 The current status of Preceramic Research in the Sagamino Plateau. Kanagawa Koko 1:1-30 (in Japanese).

YAMADA, SHOH

2002 Politics and personality: Japan's worst archaeology scandal. Harvard Asia Quarterly 6, no. 3 (Summer). http://www.asiaquarterly.com/content/view/124/

YAMAOKA, TAKUYA

2009 A Study of Lithic Material Uses during the Early Upper Paleolithic. Ph.D. diss. Tokyo Metropolitan University, Tokyo (in Japanese).

Yanagida, Toshio

2006 Regional chronology of northeastern Honshu, in A Study of Regional chronologies of Paleolithic: 141-172. ed. Anzai Masahito and Sato Hiroyuki. Tokyo: Doseisha (in Japanese).

\begin{abstract}
An expansion in archaeological excavations and site identifications over the last 30 years, particularly through an increase in salvage projects and the growth of government archaeology in Japan, has made the Japanese Islands one of the most dense regions of Palaeolithic archaeological sites in East Asia. The history of Pleistocene site discoveries and chronological frameworks for Palaeolithic lithic industries are summarized, followed by a critical review of research trajectories in the accumulation of a Palaeolithic record, specifically in terms of changes in relationships among academic archaeology, government archaeology, the public, and mass media. This article also attempts to clarify the peculiar structure of current Japanese archaeology that allowed the construction of a falsified Palaeolithic prehistory by some unscrupulous researchers for 20 years until its sensational exposure by a national daily in 2000. KeYwords: Palaeolithic, Japan, government archaeology, academic archaeology, public archaeology, mass media, lithic industries.
\end{abstract}

